\title{
Verification of a Real Time Weather Forecasting System in Southern Italy
}

\author{
Luca Tiriolo, ${ }^{1}$ Rosa Claudia Torcasio, ${ }^{1}$ Stefania Montesanti, ${ }^{1}$ and Stefano Federico ${ }^{2}$ \\ ${ }^{1}$ ISAC-CNR, 88046 Lamezia Terme, Italy \\ ${ }^{2}$ ISAC-CNR, 00133 Rome, Italy \\ Correspondence should be addressed to Stefano Federico; s.federico@isac.cnr.it
}

Received 22 September 2014; Revised 20 January 2015; Accepted 20 January 2015

Academic Editor: Harry D. Kambezidis

Copyright (C) 2015 Luca Tiriolo et al. This is an open access article distributed under the Creative Commons Attribution License, which permits unrestricted use, distribution, and reproduction in any medium, provided the original work is properly cited.

\begin{abstract}
This paper shows the performance of an operational forecasting system, based on the regional atmospheric modeling system (RAMS), at $3 \mathrm{~km}$ horizontal resolution over southern Italy. The model is initialized from the 12 UTC operational analysis/forecasting cycle of the European Centre for Medium range Weather Forecasts (ECMWF). The forecast is issued for the following three days. The performance is evaluated for a whole year for the surface parameters: temperature, relative humidity, wind speed and direction, and precipitation. The verification has been performed against SYNOP stations over southern Italy. A dense non-GTS network over Calabria is used for precipitation. Results show that RMSE is about $2-3 \mathrm{~K}$ for temperature, $12-16 \%$ for relative humidity, $2.0-2.8 \mathrm{~m} / \mathrm{s}$ for wind speed, and $55-75^{\circ}$ for wind direction, the performance varying with the season and with the forecasting time. The error increases between the first and third forecast days. The verification of the rainfall forecast shows that the model underestimates the area of the precipitation. The model output statistics (MOS) is applied to all parameters but precipitation. Results show that the MOS reduces the RMSE by $0-30 \%$, depending on the forecasting time, on the season and on the meteorological parameter.
\end{abstract}

\section{Introduction}

This paper shows the performance of an operational forecasting system in Southern Italy. The forecast is made for the following three days at $3 \mathrm{~km}$ horizontal resolution and is based on the regional atmospheric modeling system (RAMS).

Southern Italy is at the centre of the Mediterranean Basin and shows a typical Mediterranean climate [1]. This climate has a strong seasonal dependence caused by the influence of the planetary-scale pressure patterns acting on the area [2-4].

In summer, the Azores anticyclone extends over the Mediterranean Basin and Southern Italy and favours the development of a dry and temperate climate. Breeze circulations develop along the coast (sea-land breezes) and inland (mountain-valley circulations) [5-7].

In winter the Azores anticyclone retreats and the Siberian high extends over Northern Europe favouring the occurrence of cyclones over Southern Italy. These cyclones may form inside the basin, often initiated as secondary cyclogenesis, or may enter the Basin from outside [8-11].
Topographic features have a major impact on the climate of Southern Italy. Among them the presence of a warm sea and the peaked orography of Apennines, running from North to South all over the country, are of particular importance.

The Central Mediterranean Sea modulates the sea-land breeze regime along coastal areas, which eventually interacts with mountain-valley flows, and, because it is a warm sea, it ensures large water vapor availability to the storms evolving over the area. If suitable conditions are met, the sea favours convective instability and heavy precipitation, as reported in several studies over Southern Italy ([12, 13], e.g.).

The presence of mountains has also a significant impact on the local weather and climate. In addition to the development of mountain-valley flows and local wind regimes caused by the interaction of the topography with the synoptic flow, the orography controls the amount and distribution of the precipitation over Southern Italy. Climate studies [4] show the existence of a precipitation gradient between the western and eastern Southern Italy caused by the presence of the Apennines. Moreover, topography enhances local 
precipitation by orography uplift [14-16] or by focusing the rainfall in localized spots [17].

All the above characteristics make Southern Italy a challenging and interesting country for climate and weather studies. However, most of the bibliography focusing on that area is based on a case study approach and refers to the study of severe weather [18]. So, the verification of numerical weather prediction systems over Southern Italy is still lacking, particularly for parameters different from precipitation.

The aim of this work is to evaluate the performance of the forecast at high spatial $(3 \mathrm{~km})$ and temporal $(\mathrm{O}(1 \mathrm{~h}))$ resolution of the surface parameters: temperature, relative humidity, precipitation, wind speed, and wind direction.

The verification is performed for a whole year $(1 \mathrm{Decem}-$ ber 2012-30 November 2013) and, because of the importance of the seasonal forcing on the weather and climate of the area, the analysis is presented for each season.

Another problem considered in this paper is the improvement of the forecast of surface parameters (temperature, relative humidity, and wind speed and direction) by a statistical method, namely, the model output statistics (MOS, $[19,20]$ ). Indeed, the prediction of surface parameters over complex terrain, as that of Southern Italy, is difficult and is affected by dynamical and physical errors. In addition to shortcomings in the physical parameterizations and in the dynamics of the model, subgrid phenomena, as those induced by the presence of small water bodies or local topography, have an important impact on the forecast. As a consequence of these issues, the forecast is affected by systematic errors that can be reduced by statistical methods [21, 22].

In this paper the performance of a simple MOS, with one predictor for each predictand, is investigated, and the statistical robustness of the MOS improvement is evaluated.

The paper is organized as follows: in Section 2 we present the RAMS model configuration, the observational dataset used for the verification, and the statistical scores used for the forecast evaluation; the scores are shown in Section 3 as well as the impact of the MOS on the forecast statistics.

\section{Data and Methodology}

2.1. The RAMS Model Configuration. The simulations of this study are produced by the RAMS model. A detailed description of the RAMS model is given in [23] while the following is a brief description of the model setup. The RAMS model is also operational in southern Italy [24], and the results of this paper show an upgrade of that model setting. Two twoway nested domains at $12 \mathrm{~km}$ and $3 \mathrm{~km}$ horizontal resolutions, respectively, are used (Table 1, Figure 1(a)). The first grid covers the Central Mediterranean Basin while the second extends over the whole of Southern Italy. Thirty-five vertical levels, up to $21797 \mathrm{~m}$ in the terrain-following coordinate system, are used for both domains. Levels are not equally spaced: layers below $1500 \mathrm{~m}$ a.g.l. are between 50 and $200 \mathrm{~m}$ thick, whereas layers in the middle and upper troposphere (>7000 $\mathrm{m}$ a.g.l.) are $1000 \mathrm{~m}$ thick.

The land ecosystem-atmosphere feedback model (LEAF) is used to calculate the exchange between soil, vegetation, and
TABLE 1: RAMS grid-setting. NNXP, NNYP, and NNYZ are the number of grid points in the west-east, north-south, and vertical directions. $L_{x}(\mathrm{~km}), L_{y}(\mathrm{~km})$, and $L_{z}(\mathrm{~m})$ are the domain extension in the west-east, north-south, and vertical directions. DX $(\mathrm{km})$ and DY $(\mathrm{km})$ are the horizontal grid resolutions in the west-east and north-south directions. CENTLON and CENTLAT are the geographical coordinates of the grid centers.

\begin{tabular}{lcc}
\hline & Domain 1 & Domain 2 \\
\hline NNXP & 261 & 254 \\
NNYP & 241 & 222 \\
NNZP & 35 & 35 \\
$L_{x}$ & $3120 \mathrm{~km}$ & $759 \mathrm{~km}$ \\
$L_{y}$ & $2880 \mathrm{~km}$ & $663 \mathrm{~km}$ \\
$L_{z}$ & $21797 \mathrm{~m}$ & $21797 \mathrm{~m}$ \\
DX & $12 \mathrm{~km}$ & $3 \mathrm{~km}$ \\
DY & $12 \mathrm{~km}$ & $3 \mathrm{~km}$ \\
CENTLAT $\left(^{\circ}\right)$ & 42.0 & 39.8 \\
CENTLON $\left({ }^{\circ}\right)$ & 12.5 & 15.7 \\
\hline
\end{tabular}

atmosphere [25]. LEAF is a representation of surface features, including vegetation, soil, lakes and oceans, and snow cover, and their influence on each other and on the atmosphere.

Explicitly resolved precipitation is computed from bulk microphysics prognostic equations for the mixing ratios of seven water categories: cloud water, rain, pristine ice, snow, aggregates, graupel, and hail [26]. Snow, aggregates, and pristine ice are assumed completely frozen; cloud water and rain are liquid water, while graupel and hail are mixedphase categories. The scheme uses a generalized gamma size-spectrum and uses a stochastic collection rather than a continuous accretion. The scheme includes a heat budget equation for each hydrometeor class, allowing heat storage and the existence of mixed phase hydrometeors.

Sub-grid-scale effect of convective and nonconvective clouds is parameterized following Molinari and Corsetti [27] who proposed a simplified form of the Kuo scheme [28] that accounts for updrafts and downdrafts.

The RAMS parameterizes the unresolved transport using $\mathrm{K}$-theory, in which the covariance is evaluated as the product of an eddy mixing coefficient and the gradient of the transported quantity. The turbulent mixing in the horizontal directions is parameterized following Smagorinsky [29], which relates the mixing coefficients to the fluid strain rate and includes corrections for the influence of the Brunt-Vaisala frequency and the Richardson number [30].

A full-column, two-stream single-band radiation scheme is used to calculate short-wave and long-wave radiation [31]. The scheme accounts for condensate in the atmosphere, but not whether it is cloud water, rain, or ice.

Using this model configuration, a one-year forecast (1 December 2012-30 November 2013) was collected. The forecast starts, for each day, at 12 UTC and lasts $84 \mathrm{~h}$ and the model output is available every hour. The first 12 hours of each forecast are spin-up time and are discarded from the verification process. This time is enough to reach a dynamical equilibrium of the physical and dynamical components of 


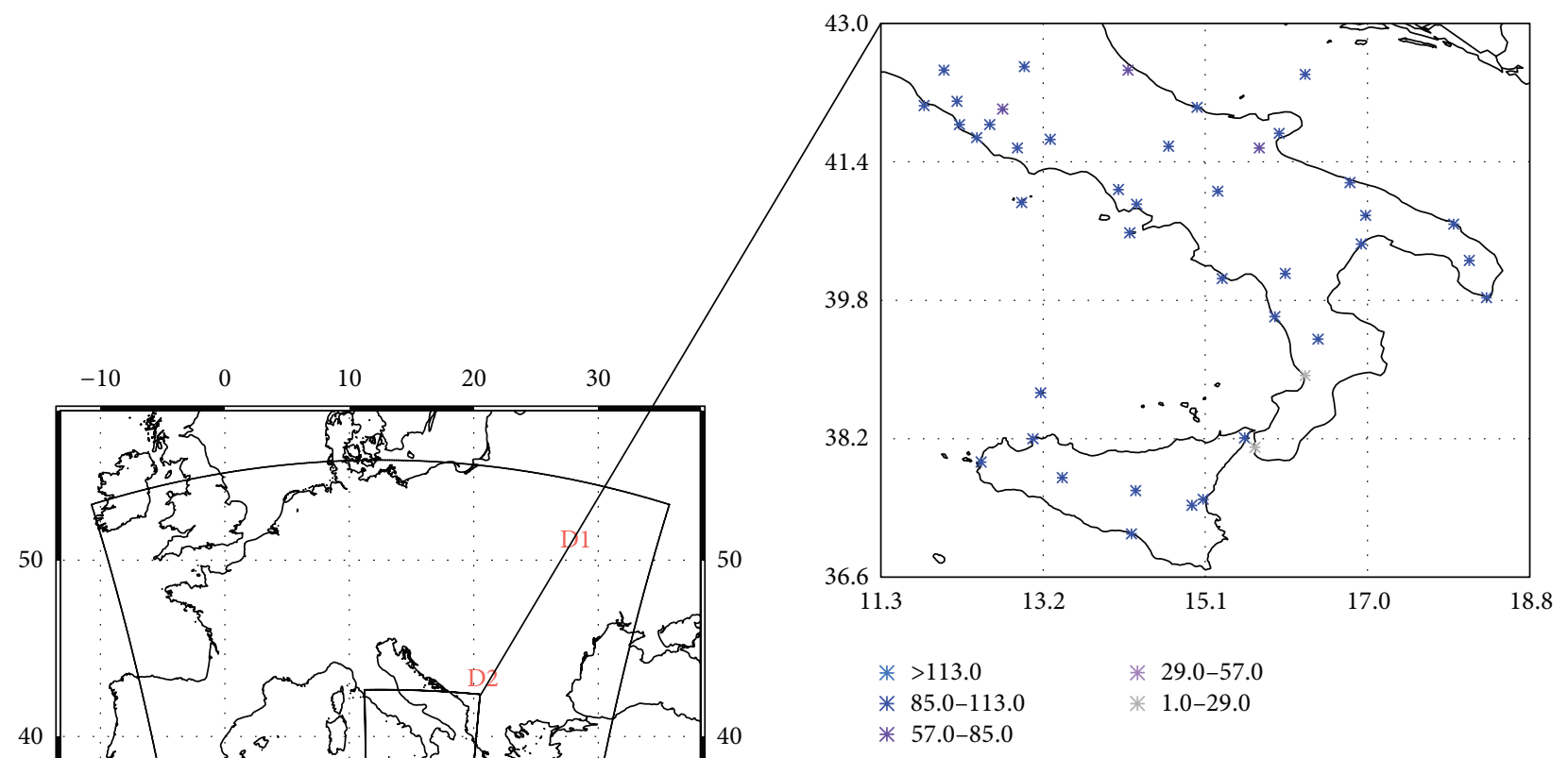

(b)

30

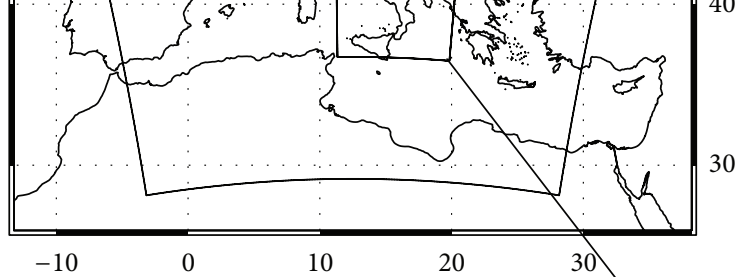

(a)

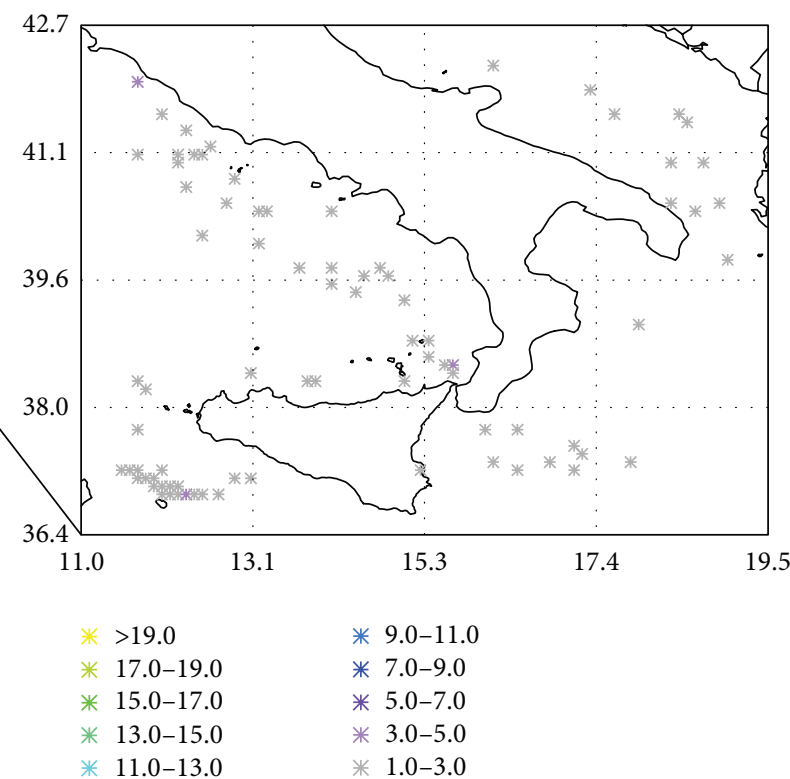

(c)

FIGURE 1: (a) RAMS domains: (b) SYNOP land stations over the second domain. The colours of the stations show the reports multiplicity for spring 2013 and for the 18 hours of forecasting time and (c) SYNOP mobile stations over the second domain. The colours of the stations show the reports multiplicity for spring 2013 and for the 60 hours of forecasting time. The positions and number of the mobile reports change with time.

the model, as reported in a previous study [32]. Initial and boundary conditions are given by the ECMWF operational analysis and forecast cycle at 12 UTC.

\subsection{Observational Data and Verification for Temperature, Rel-} ative Humidity, Wind Speed, and Wind Direction. The observational dataset used to quantify the model performance for temperature, relative humidity, wind speed, and wind direction is formed by the reports of the SYNOP stations, both land and mobile, which are distributed through the GTS.
For the verification, the forecast is bilinearly interpolated to the position of the SYNOP observations. Statistics have been calculated over the RAMS nested domain (southern Italy) where GTS counts 42 surface land stations (Figure 1(b)). Available reports vary from 10 to 42 for each forecasting time depending on the day. Even if there are comparatively more stations in the coastal areas than inland, the reports of the SYNOP stations are reliable and resilient giving a unique sample for the forecast verification. This is important for evaluating future developments of the operational model. 


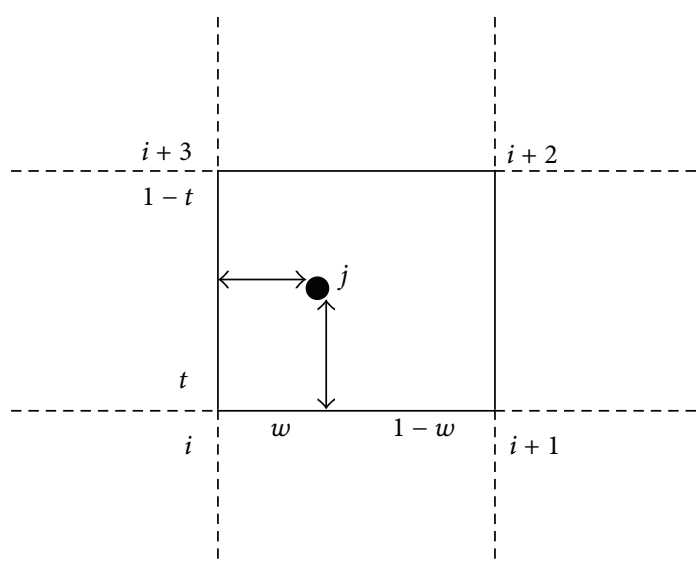

FIgURE 2: Bilinear interpolation. The weights $w$ and $t$ are the distances between the station $j$ and the grid point $i$.

In addition to the 42 SYNOP land stations, the reports of SYNOP mobile stations are considered (Figure 1(c)) in this paper. However, the reports available for mobile stations are much less than those of the land stations. For example, Figure 1(b) shows the multiplicity of the reports for each of the 42 SYNOP land stations for the $t+18$ hours forecast in spring. The multiplicity is computed by summing over the whole spring. The multiplicity is larger than 85 for most stations.

The situation is different for mobile stations. Figure 1(c) shows the reports multiplicity for mobile stations for the whole spring at $t+60$, the forecasting time being chosen to maximize the available reports. For this time there are 80 mobile stations, nevertheless the multiplicity is, for most cases, one.

Similar results to those of Figures 1(b) and 1(c) are found for other seasons and forecasting times showing the much larger number of data available for land stations compared to mobile. This point will be further considered in Section 3.1.

For temperature a simple correction was implemented to account for the gap between the real altitude of the surface weather station and that of the RAMS model corresponding to the station coordinates. In particular, referring to Figure 2, the temperature at the station $j$ is given by

$$
\begin{aligned}
T_{j}= & (1-w)(1-t)\left(T_{i}-\gamma\left(z_{i}-z_{j}\right)\right) \\
& +w(1-t)\left(T_{i+1}-\gamma\left(z_{i+1}-z_{j}\right)\right) \\
& +w t\left(T_{i+2}-\gamma\left(z_{i+2}-z_{j}\right)\right) \\
& +(1-w) t\left(T_{i+3}-\gamma\left(z_{i+3}-z_{j}\right)\right),
\end{aligned}
$$

where $w$ and $t$ are the weights of the bilinear interpolation, $z$ is the altitude, $T$ is the temperature, and $\gamma$ is the vertical temperature gradient. This gradient is computed from the model output considering the grid points surrounding the station.

For other parameters the bilinear interpolation is used without the gradient adjustment (i.e., (1) with $\gamma=0$ ).
Different statistical scores have been computed as follows.

(i) Bias or mean error (hereafter also BIAS) measures the mean difference between simulation and observation:

$$
\text { BIAS }=\frac{1}{N} \sum_{i=1}^{N}\left(\text { Forecast }_{i}-\text { Observation }_{i}\right) .
$$

(ii) Mean absolute error (hereafter also ABS) measures the mean amplitude of the simulation error with respect to the observation:

$$
\mathrm{ABS}=\frac{1}{N} \sum_{i=1}^{N} \mid \text { Forecast }_{i}-\text { Observation }_{i} \mid
$$

(iii) Root mean square error (hereafter also RMSE) measures the mean square gap between observed and modelled data:

$$
\text { RMSE }=\sqrt{\frac{1}{N} \sum_{i=1}^{N}\left(\text { Forecast }_{i}-\text { Observation }_{i}\right)^{2}},
$$

where $N$ is the total number of observation-forecast pairs entering the statistic. This number varies from case to case depending on the number of available GTS reports.

Errors have been calculated for 12 months (1 December 2012-30 November 2013). Considering the importance of the seasonal cycle in the Southern Italy climate, statistics are shown for different seasons.

For the verification of the precipitation forecast a different dataset was used because the data available through the GTS are too sparse and too few for an adequate verification of the field. The dataset and the methodology followed to verify the precipitation field are discussed in Section 3.2.

\section{Results}

3.1. Verification of the Model Performance. Figure 3 shows the BIAS and RMSE for temperature. Both statistics are shown from $t+12$ to $t+84$, where $t$ is the initial forecasting time. The figure shows the results every 12 hours. Hours $12,36,60$, and 84 denote $00 \mathrm{UTC}(\mathrm{LST}=\mathrm{UTC}+1 \mathrm{~h})$, while hours 24,48 , and 72 are 12 UTC.

Excluding the BIAS for spring at $t+84$, when a small positive value $(<0.1 \mathrm{~K})$ is shown, all values are negative, and the forecast underestimates observations. There is no particular dependency on the season, the largest absolute values being for different seasons depending on the forecasting time. The BIAS shows a clear diurnal cycle with larger absolute values at $12 \operatorname{UTC}(t+24, t+48, t+72)$.

Figure $3(\mathrm{~b})$ shows the RMSE for temperature. Values are around $2 \mathrm{~K}$ for most forecasting times and seasons. Smallest values are for winter and spring, while the largest values are for summer and fall. An important behaviour shown by RMSE is the diurnal cycle in summer. The RMSE is around $2 \mathrm{~K}$ at $00 \mathrm{UTC}$ while it increases up to $3.2 \mathrm{~K}$ for $12 \mathrm{UTC}$. It is also noticed that the small RMSE increase with forecasting time.

Considering statistics for the relative humidity (Figure 4), the bias shows negative values for most forecasting times and 


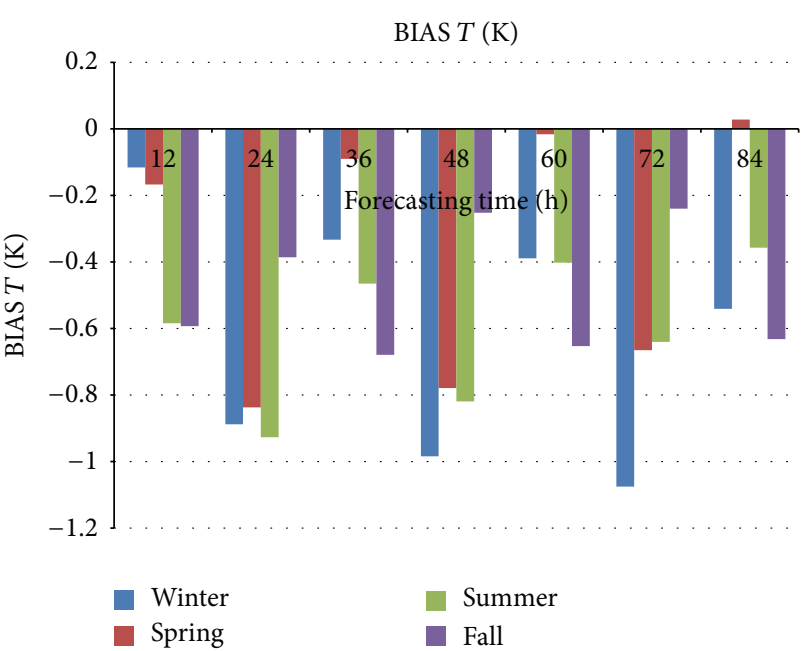

(a)

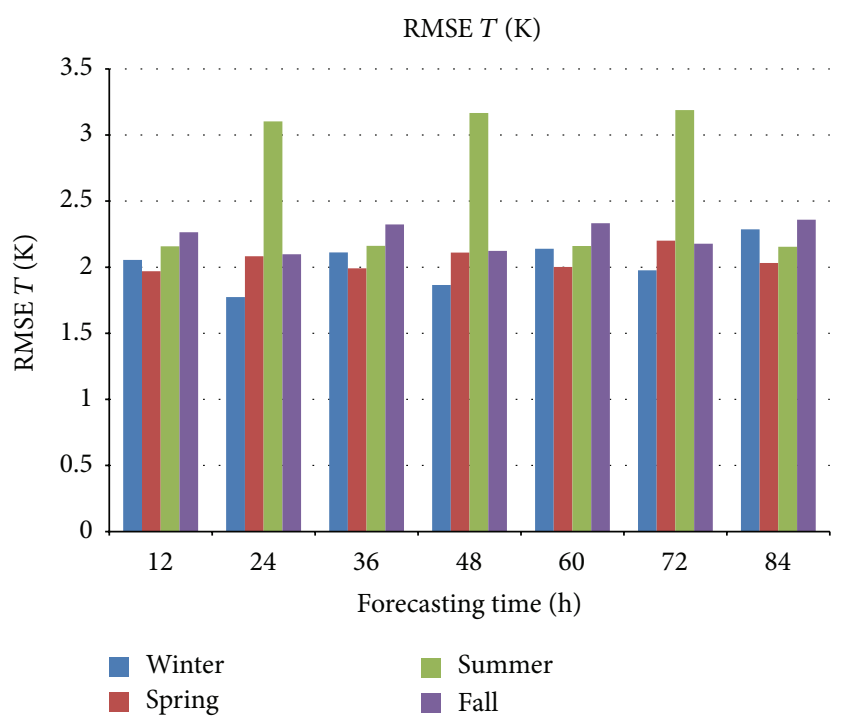

(b)

FIgURe 3: BIAS (a) and RMSE (b) for temperature for the four seasons.

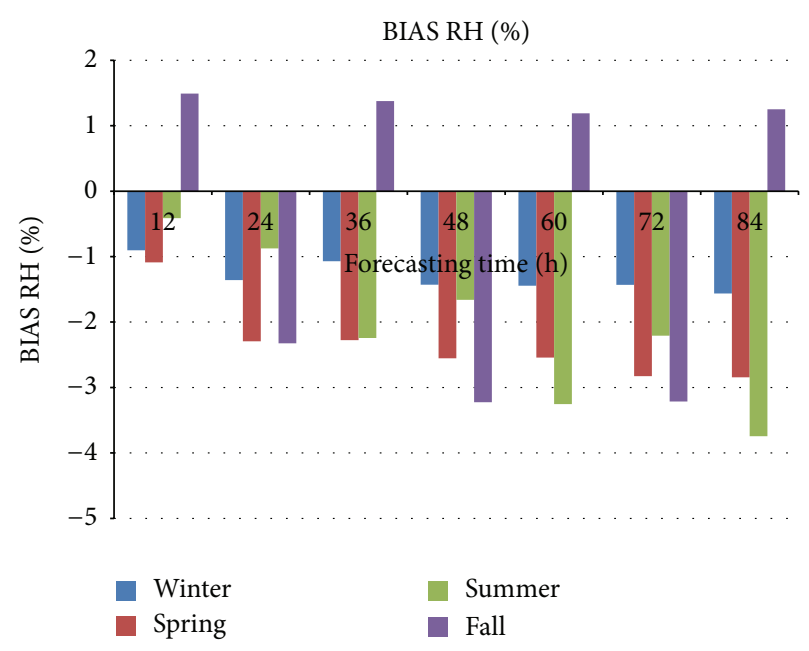

(a)

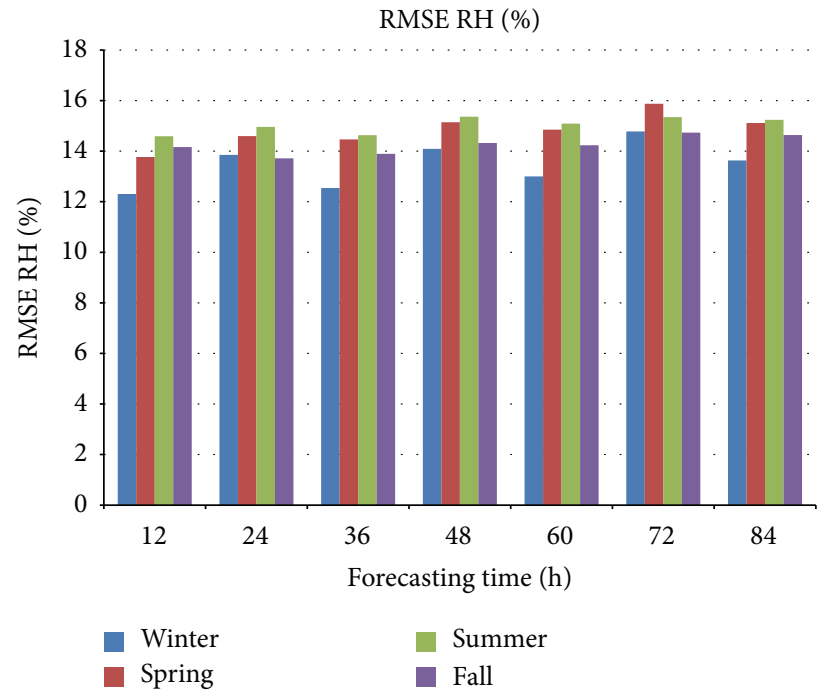

(b)

FIGURE 4: BIAS (a) and RMSE (b) for relative humidity for the four seasons.

seasons. In particular, the values decrease from $-1 \%$ at $t+12$ to $-3 \%$ at $t+84$ for spring, meanwhile in winter from $-1 \%$ at $t+12$ to $-1.5 \%$ at $t+84$. A diurnal cycle is shown for summer with largest absolute values of the BIAS occurring at 00 UTC (up to $-3.5 \%)$. Fall shows a positive BIAS (1.5\%), almost constant with the integration time.

The RMSE (Figure 4(b)) shows a rather constant value for different forecasting times (12-16\% depending on the season). The smallest values are for winter and fall, while the largest errors occur in summer and spring. As for temperature, there is a small increase of the RMSE with forecasting time.

Considering the statistics for wind speed (Figure 5) we notice a different behaviour for winter and fall compared to summer and spring. In winter and fall the forecast underestimates the observed values for all forecasting times, the value ranging from $-0.3 \mathrm{~m} / \mathrm{s}$ to $-0.7 \mathrm{~m} / \mathrm{s}$. In summer and spring a clear diurnal cycle is shown with negative values at 00 UTC and small values, positive or negative depending on the forecasting time, for 12 UTC.

The RMSE for wind speed (Figure 5(b)) ranges between 2.0 and $2.8 \mathrm{~m} / \mathrm{s}$. The largest values are for winter and spring and the smallest values for summer and fall.

Figure 6 shows the BIAS (Figure 6(a)) and RMSE (Figure 6(b)) for the wind direction. The BIAS ranges between -6.5 and 3 degrees, depending on the season and forecasting time. No particular behaviour of the BIAS with 


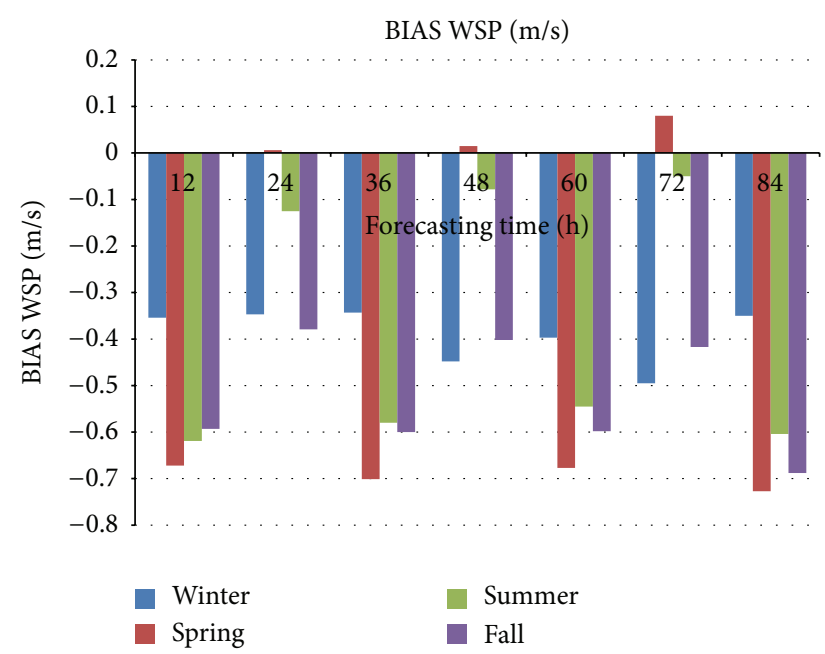

(a)

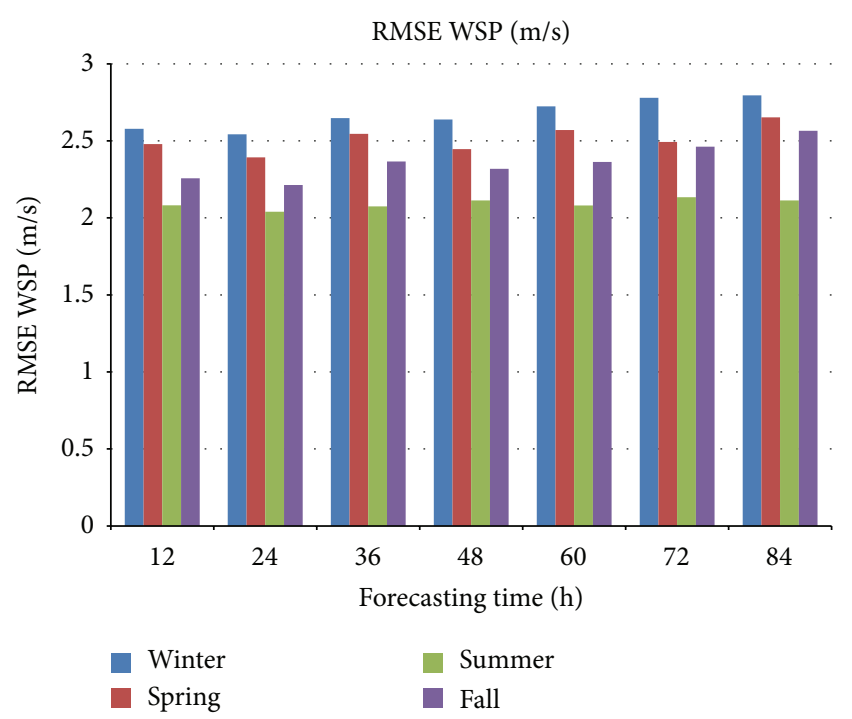

(b)

FIGURE 5: BIAS (a) and RMSE (b) for wind speed for the four seasons.

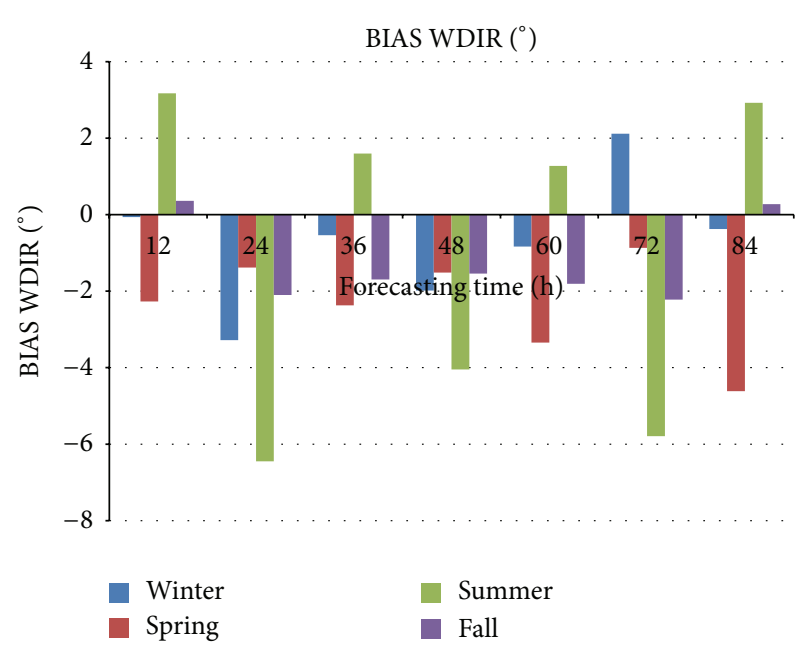

(a)

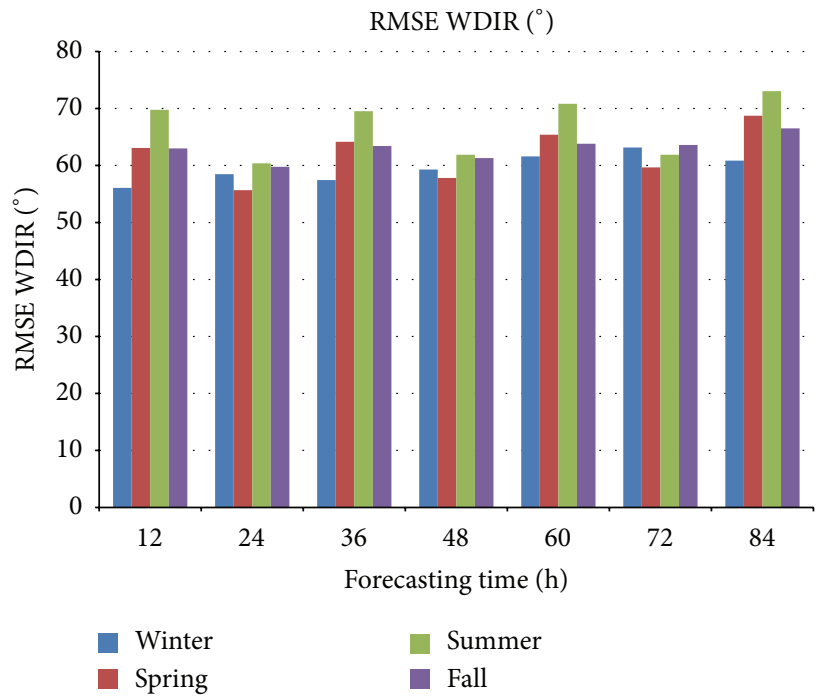

(b)

Figure 6: BIAS (a) and RMSE (b) for wind direction for the four seasons.

the season or forecasting time is shown in Figure 6(a). This is expected considering the rather homogeneous distribution of the verification dataset (Figures 1(b) and 1(c)) and, for coastal stations, with the sea to the west or east of the surface station.

Values for the RMSE of wind direction range between $55^{\circ}$ and $75^{\circ}$ depending on the season and forecasting time. There is a small increase of the error with forecasting time superimposed to a diurnal cycle. As expected, this cycle is more evident in summer, when the largest errors occur at 00 UTC.

Comparing the results of Figures 5 and 6 for summer and winter we notice that the wind speed has a lower error in summer, while the wind direction has a lower error in winter. This behaviour is caused by the local circulations, which dominate the local climate in summer. In particular, because several SYNOP stations (Figures 1(b) and 1(c)) are near the sea or over maritime areas, the sea-breeze plays a major role $[33,34]$.

In summer, the wind speed is lower and has a larger diurnal cycle than in winter. In these conditions the wind direction is variable, especially for low wind speed, as at 00 UTC (Figure 6). In winter the wind speed is larger than in summer and the circulations are focused on specific directions, which are determined, from case to case, by the synoptic scale forcing.

The forecast is less able to follow the larger variability of the wind direction in summer compared to the more focused 


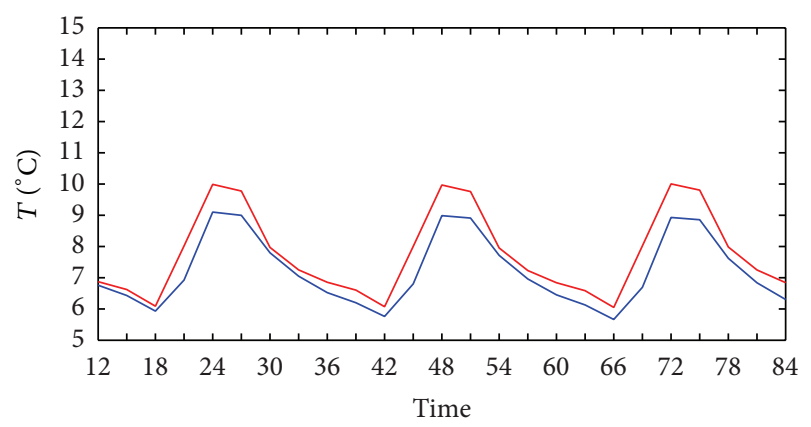

- Forecast

- Observations

(a)

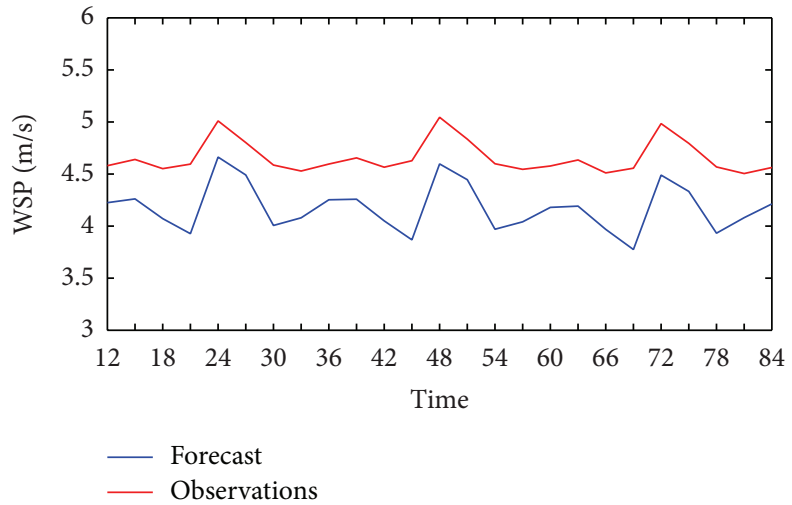

(b)

FIgURE 7: Time series of the forecast and observations for temperature (a) and wind speed (b) in winter.

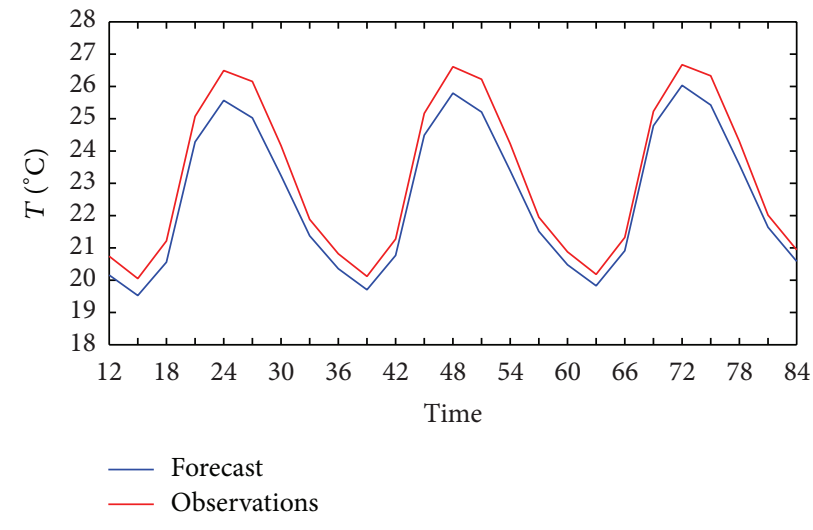

(a)

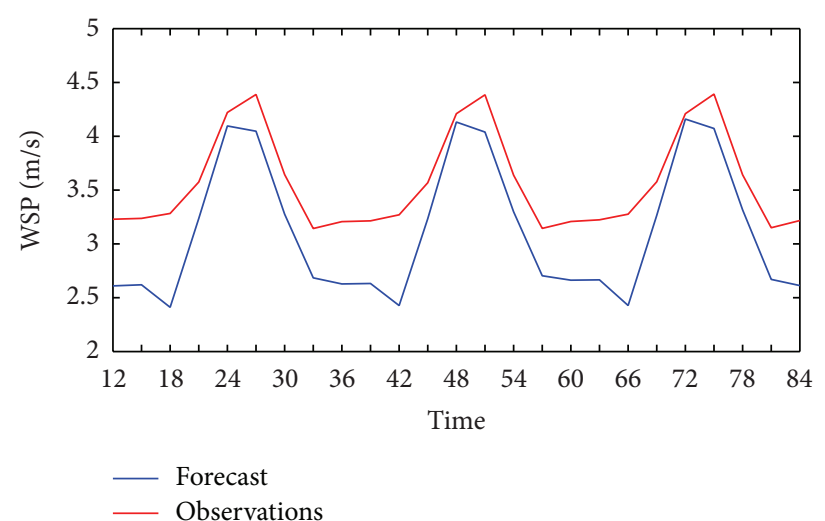

(b)

FIgURE 8: Time series of the forecast and observations for temperature (a) and wind speed (b) in summer.

direction in winter, so the errors for wind directions are larger in summer than in winter.

On the other hand, the model is more able to predict the lower wind speed and its regular diurnal cycle in summer compared to the stronger winds occurring in winter.

To analyse more in detail the diurnal cycle of the errors and the different behaviour among seasons, Figures 7 and 8 show the time series of the observations and forecast for temperature and wind speed in winter and summer. Time series are computed by averaging the observations and the forecast over the second domain of the RAMS forecast.

Considering the temperature in winter and summer, we notice the larger amplitude of the diurnal cycle in summer. Both in winter and summer the model underestimate the observed temperature, especially during the daylight hours, confirming the results of Figure 3(a).

Wind speed is larger in winter (Figure 7(b)) than in summer (Figure 8(b)) showing the importance of the synopticscale forcing in this season of the year. In summer there is a clear diurnal cycle of the wind speed, caused by the local circulations. A wind-speed diurnal cycle is also present in winter, but its amplitude is lower than in summer. It is also noticed that the forecast overestimates the amplitude of the diurnal cycle in winter, and this is another source of error causing a larger RMSE for wind speed in winter compared to summer.

We also notice that the forecast underestimates the wind speed both in summer and winter (see also Figure 5(a)).

The statistics of Figures 3-6 show the results considering both land and mobile SYNOP reports. It would be interesting to consider the model performance over maritime areas and eventually compare this result with that found over the land.

This analysis is difficult in the context of this paper because the number of records available from mobile stations is small in absolute value, and much smaller than the reports of land (motionless) stations. Figure 9(a) shows the number of records for the land and mobile stations for the wind speed in summer. The number of records available for SYNOP land stations is between 1900 and 3000, depending on the forecasting time, while the number of reports for SYNOP mobile is less than 100 for all forecasting times. Similar results are found for other seasons and for other parameters, confirming the much smaller number of data for maritime areas compared to the land. Moreover, the result of Figure 9(a) shows that the statistics of Figures 3-6 are by far determined by the SYNOP-land stations. 


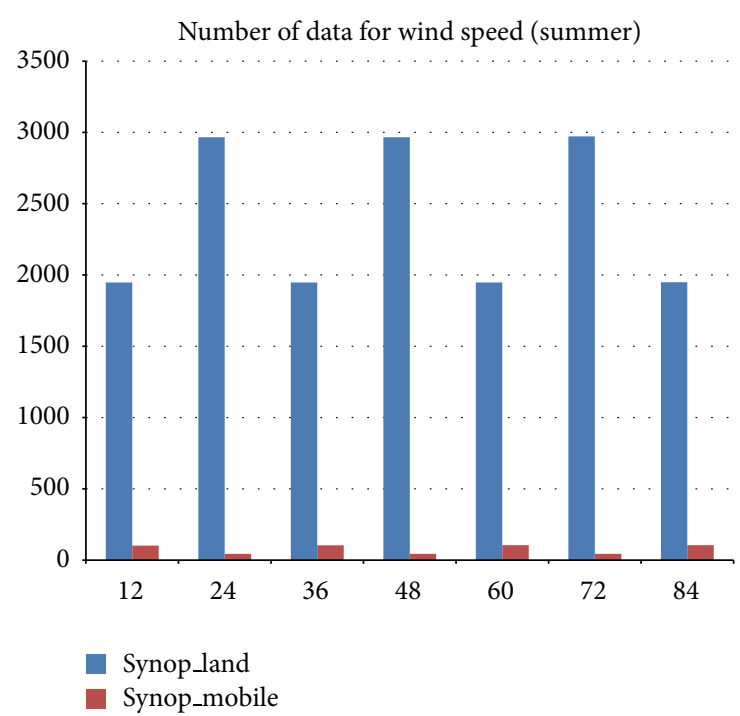

(a)

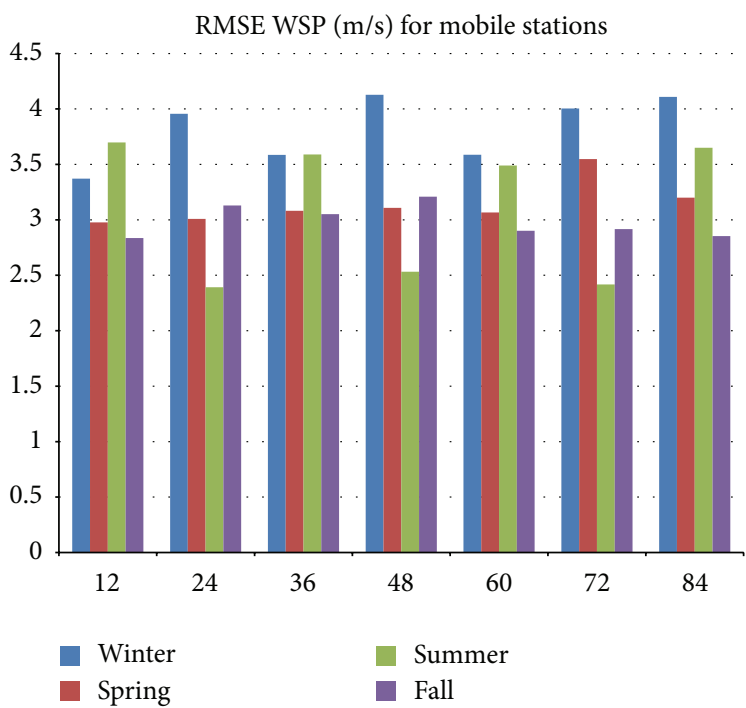

(b)

FIGURE 9: (a) Number of data available for land and mobile SYNOP stations, (b) as in Figure 5(b) for mobile SYNOP stations.

With the limitation of the small dataset available, the errors found over maritime areas are in line with those for the whole dataset for all parameters but the wind speed. More specifically, the Bias and RMSE for temperature, relative humidity and wind direction for maritime areas are sometimes smaller sometimes larger than those of Figures 3, 4, and 6 , but they do not show a particular behaviour when compared to the results for the whole dataset.

For the wind speed, however, errors are larger over maritime areas compared to land (Figure 9(b)). This is verified for all seasons and forecasting times. The wind speed bias for the whole dataset is negative for most forecasting times for all seasons, showing the model tendency to underestimate surface winds (Figure 5(a)). The underestimation of surface winds is exacerbated for maritime areas (not shown) determining a larger RMSE. The underestimation of the surface wind speed, especially for maritime areas, could be the result of several factors. Among others, errors in the physical parameterization of the RAMS model, the lack of coupling between the atmospheric model and a sea-wave model, the lower number of in situ data assimilated by atmospheric models over the sea compared to those over land, could play a role. The detailed investigation of these issues, however, needs a larger dataset and a larger domain extension than those considered in this work for studying the topic in different topographical and meteorological conditions. For these reasons, the assessment of the model performance over maritime areas and its comparison with performance over the land will be investigated in detail in future studies.

3.2. Verification of the Precipitation Forecast. As stated at the end of Section 2, the GTS data for precipitation are too few and too sparse for an adequate verification of the forecast, so this field was verified over the Calabria Region (Figure 10) on a daily basis, that is, for the first, second and third day forecasts. The choice of Calabria is motivated by three main

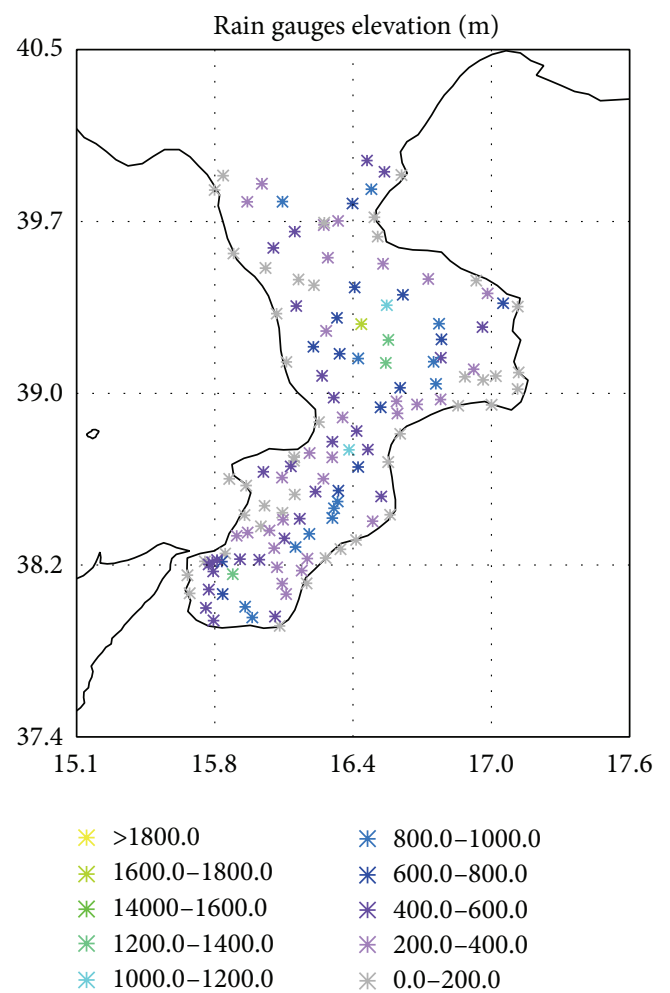

FIgURE 10: Rain gauges available for Calabria. The elevation above sea level of the stations is shown in different colours.

reasons: (a) Calabria is representative of the Mediterranean climate [4]; (b) Calabria has a dense network of non-GTS rain gauges. More specifically we consider a network of 135 rain gauges distributed rather uniformly over the region (Figure 10); (c) a database of daily precipitation is maintained at ISAC-CNR for Calabria [35], ensuring a good quality 
of the data, the quality check procedure being detailed in Federico et al. [35].

The four-point method [36] was adopted for the verification of the precipitation forecast. In this method, the differences between the model and observed precipitation at the four grid points surrounding the station are computed. Then the model precipitation having the smallest difference with the observation is considered as the predicted value. In this way a shift in the precipitation field up to $3 \sqrt{2}=4.2 \mathrm{~km}$ is considered negligible.

Before applying the four-point method, precipitations of two or more stations falling in the same grid-cell of the RAMS model are grouped in a single super-observation, whose precipitation is given by the average of the precipitations recorded by the stations inside the (same) grid-cell.

Statistical verification was performed by computing $2 \times$ 2 contingency tables for different precipitation thresholds, namely, $0.2,1,5,10,20,40$, and $60 \mathrm{~mm}$, being $60 \mathrm{~mm}$ generally considered as a threshold for severe precipitation events in the Mediterranean Basin [18]. In particular, starting from the hits $(a)$, false alarms $(b)$, misses $(c)$, and correct no forecasts $(d)$, the probability of detection (POD), false alarm rate (FAR), the bias, and the equitable threat score (ETS) were computed [22]:

$$
\begin{aligned}
\mathrm{POD} & =\frac{a}{a+c}, \\
\mathrm{FAR} & =\frac{b}{a+b}, \\
\mathrm{Bias} & =\frac{a+b}{a+c}, \\
\mathrm{ETS} & =\frac{a-a_{r}}{a+b+c-a_{r}} ; \quad a_{r}=\frac{(a+b)(a+c)}{a+b+c+d} .
\end{aligned}
$$

The performance of the precipitation forecast was evaluated for the three forecast days, nevertheless no particular differences were found among the three days, so the following discussion focuses on the second day of forecast.

Figure 11 shows the Bias, POD, FAR and ETS for the second day of forecast for the whole year. The Bias is 0.9 for the $0.2 \mathrm{~mm}$ threshold, but it largely decreases for other thresholds. Its value is about 0.3 for the $10 \mathrm{~mm}$ threshold and 0.2 for thresholds greater than $10 \mathrm{~mm}$. The Bias shows that the model underestimates the precipitation area especially for thresholds larger than $5 \mathrm{~mm}$ (Bias < 0.4).

Although the Bias has small value, the precipitation pattern forecast is correctly located. This is shown by the value of the ETS, which is larger than zero for all thresholds, showing the usefulness of the forecast. So, while the model underestimates the precipitation area, it correctly predicts its position.

The POD score decreases with increasing thresholds. In particular for the 0.2 and $1 \mathrm{~mm}$ thresholds, POD is larger than 0.6 showing that more than $60 \%$ of the precipitation forecast above these thresholds is co-located with observations. The similarity between POD and Bias values, especially for thresholds larger than $5 \mathrm{~mm}$, shows that the hits $(a)$ and misses $(c)$ are both much larger than false alarms $(b)$. For

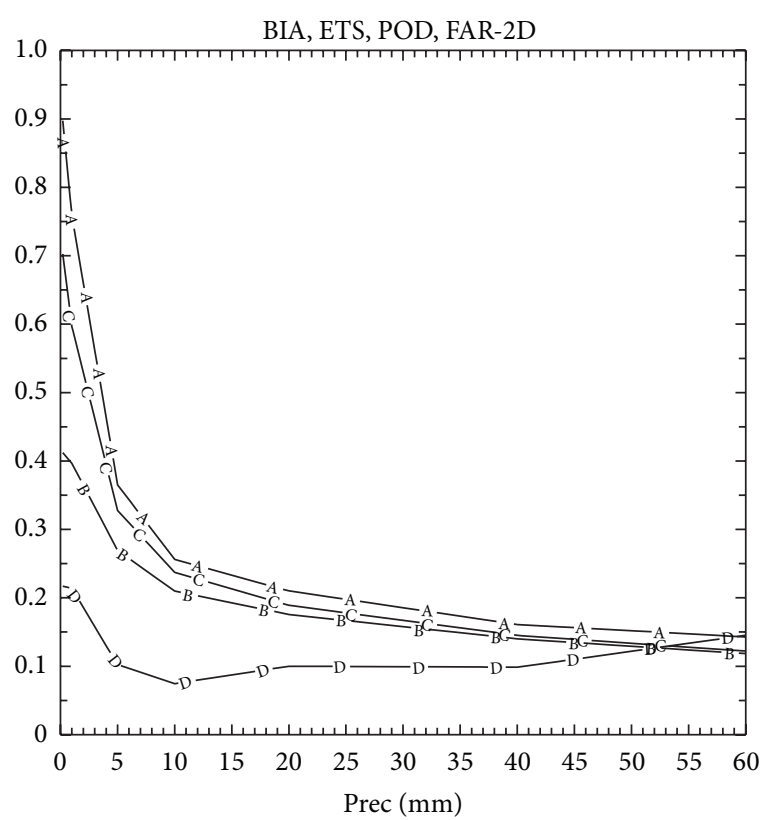

FIGURE 11: Precipitation scores for the whole period (1 December 2012-30 November 2013) for the daily precipitation thresholds: 0.2 , $1,5,10,20,40$, and $60 \mathrm{~mm}$. A = Bias, B = ETS, C = POD, and D = FAR.

example, for the $40 \mathrm{~mm}$ threshold, $a=128, b=14$ and $c=754$.

The FAR score shows a decrease up to the $10 \mathrm{~mm}$ threshold, then it steadily increase, this behaviour being typical of several meteorological models [37]. It is worth noting that the POD is larger than FAR for all thresholds but $60 \mathrm{~mm}$, showing a good forecast performance, despite the dryness of the forecast.

Considering the scores for the different seasons of the year, we note that the behaviours for winter, spring and fall are similar to those found for the whole year, whilst summer has a different behaviour of the scores. This is expected because of the change of the precipitation regime over Calabria in summer. Indeed, while in spring, fall and winter the precipitation is mainly associated with the passage of large scale storms (including subsynoptic systems, whose spatial extension is, however, larger than Calabria peninsula [18]), in summer local forcing (e.g., the orography, the sea surface temperature, the stability of the lower atmosphere) is a key factor for triggering convection, and the precipitation is often localized in spots, which are less extended compared to the precipitation patterns found in other seasons. The precipitation forecast is more difficult in summer than in other seasons [18].

Figure 12 shows the precipitation scores for summer. The Bias is larger than 1 for the 0.2 and $1 \mathrm{~mm}$ daily precipitation values, then it decreases for larger thresholds, being zero for the $20 \mathrm{~mm}$ threshold. The ETS is between 0.15 and 0.4 up to the $10 \mathrm{~mm}$ threshold, then it decreases to zero for the $20 \mathrm{~mm}$ threshold. The POD decreases from 0.8 (0.2 $\mathrm{mm}$ threshold) to 0 ( $20 \mathrm{~mm}$ threshold), while the FAR decreases from 0.2 to $10 \mathrm{~mm}$ thresholds, then it is 1 for the $20 \mathrm{~mm}$ threshold. 


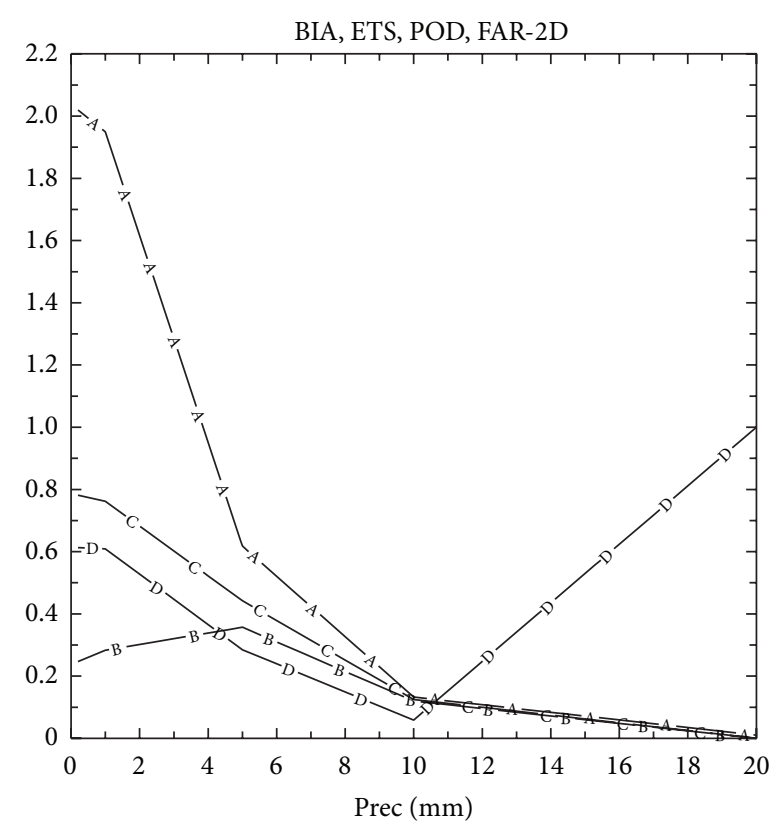

Figure 12: As in Figure 11 but for summer.

The results of Figure 12 show that the model is unable to catch the localized moderate-intense precipitation spots (i.e., $>10 \mathrm{~mm}$ /day) occurring in Calabria in summer [35]. On the contrary, the model is able to catch, and overestimate, the small-precipitations triggered by local circulations, which are typical in Calabria in summer [7].

3.3. Statistical Forecasting by MOS. In this paragraph we show the impact of a widely used postprocessing technique, that is, the MOS [19-22], for improving the forecast.

There are two basic reasons for applying the MOS to the output of numerical weather prediction models (NWPs).

(a) The NWPs are not perfect and have systematic errors (biases). Statistical forecast may compensate and correct those biases.

(b) The NWPs homogenize surface conditions, as they represent reality with a finite number of grid points. This representation misses important small-scale effects (caused, e.g., by the presence of small surface water bodies or local topography) that may have an important impact on local weather and climate. Statistical relationship may be derived between the NWPs output and the desired forecast quantities to give a closer representation of the real world.

The MOS has been applied to the meteorological parameters: temperature, relative humidity, wind speed and wind direction.

For each predictand one predictor is used. In particular, the predictand of the MOS regression curve is the meteorological parameter observed at the station while the predictor is the model forecast for the predictand.

The following methodology is employed to quantify the impact of the MOS on the forecast: the MOS regression equation is computed using $90 \%$ of the data and is applied to the remaining $10 \%$ of data to give the forecast. This procedure is repeated 50 times, randomly selecting the $90 \%$ of the data used for the computation of the MOS regression. For each MOS forecast, RMSE has been computed and compared to that obtained without using the MOS.

Hereafter, for brevity, results are presented only for spring, nevertheless similar results were found for other seasons.

Figure 13(a) shows the difference between RMSEs ( $\triangle$ RMSE) without using the MOS and using the MOS for surface temperature. A positive value means that the forecast is improved by the MOS. Considering the average of the $\triangle$ RMSE for the fifty-MOS applications, an improvement of $\sim 0.4 \mathrm{~K}$ is gained for all forecasting times. The improvement is about $20-30 \%$ of the RMSE without MOS (i.e., about $2 \mathrm{~K}$ for spring, Figure 3(b)), showing an important impact of the MOS on the forecast. The result is statistically robust because there is an improvement for all the fifty MOS and the 25th percentile shows an improvement larger than $0.2 \mathrm{~K}$ for all forecasting times, that is, larger than $10 \%$ of the RMSE without MOS.

To further quantify the forecast improvement by MOS, we performed the forecast of the spring season without using the second RAMS domain ( $3 \mathrm{~km}$ horizontal resolution, Figure 1). The horizontal resolution of this forecast is $12 \mathrm{~km}$ and, considering the complex orography of the studied area, an important impact of the horizontal resolution on the forecast of surface temperature is expected. The dotted line (G1-G2) in Figure 13(a) shows the RMSE difference between the forecast using only one grid (G1, $12 \mathrm{~km}$ horizontal resolution) and the forecast using both domains (G1, G2, $3 \mathrm{~km}$ horizontal resolution). A positive difference means an improvement of the forecast using both domains.

As expected, the impact of increasing the horizontal resolution is noticeable with maximum values of the RMSE difference between G1 and G2 around 0.6 K. It is interesting to note, however, that the improvement gained by enhancing the horizontal resolution from $12 \mathrm{~km}$ to $3 \mathrm{~km}$ is comparable with that gained by the MOS. Stated in other terms, using the MOS on the second grid forecast has a positive impact on the forecast, which is of the same order of that given by increasing the horizontal resolution from 12 to $3 \mathrm{~km}$.

These results show the importance of using a statistical correction as MOS to the RAMS forecast, especially considering the limited amount of computing time required by the MOS.

Figure 13(b) quantifies the impact of the MOS on the relative humidity forecast. The improving using the MOS is about $2.5 \%$ that must be compared with the RMSE of $\sim 15 \%$ without using the MOS (Figure 4(b)). Results are statistically robust and the improvement of the 25th percentile is larger than $2 \%$ for most forecasting times. The improvement gained by MOS is larger than that given by enhancing the horizontal resolution from $12 \mathrm{~km}$ to $3 \mathrm{~km}$.

The result for the wind speed, Figure 13(c), shows again a positive and important impact of the MOS. The $\triangle \mathrm{RMSE}$ is above $0.3 \mathrm{~m} / \mathrm{s}$ for all forecasting times, that is, between 10 


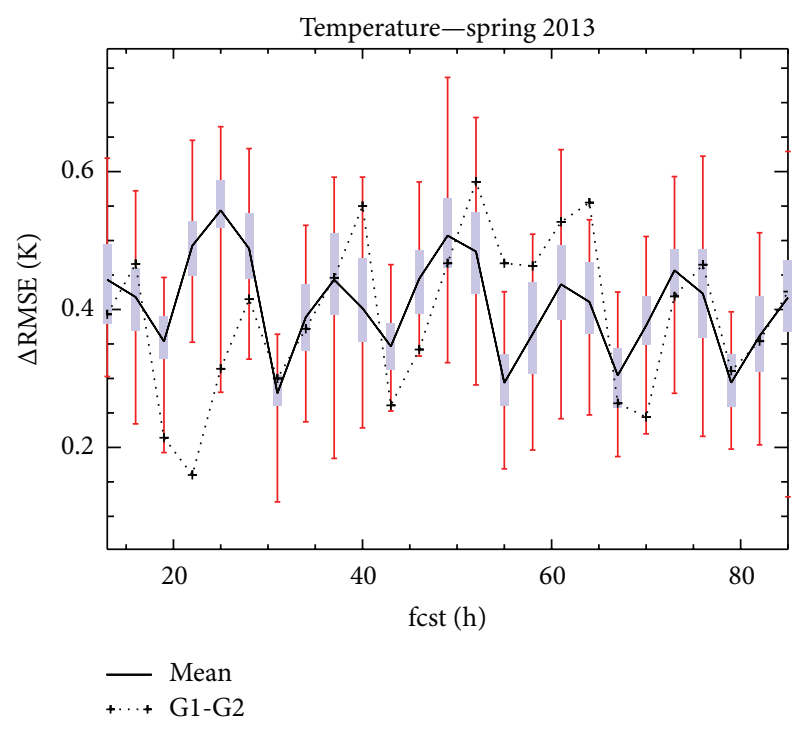

(a)

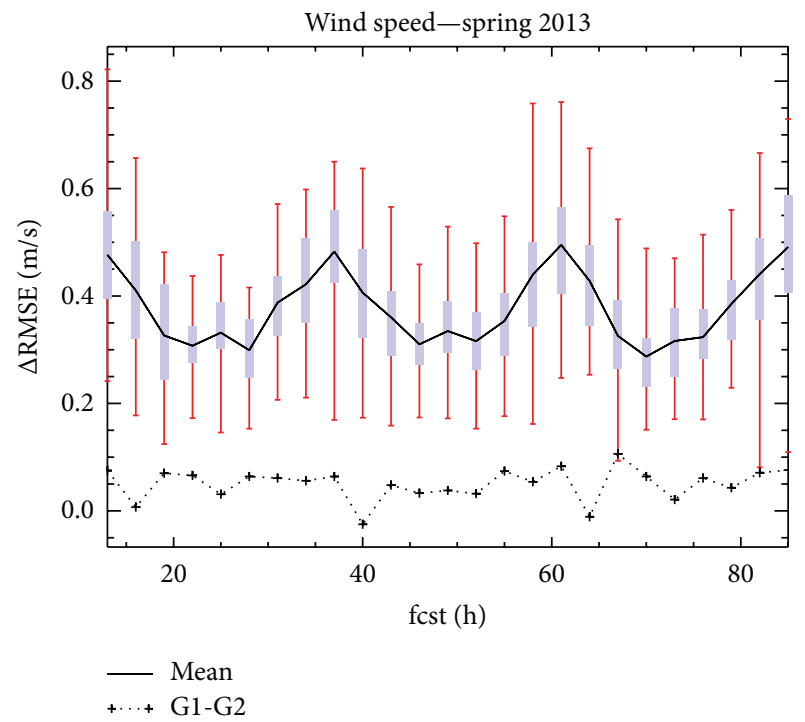

(c)

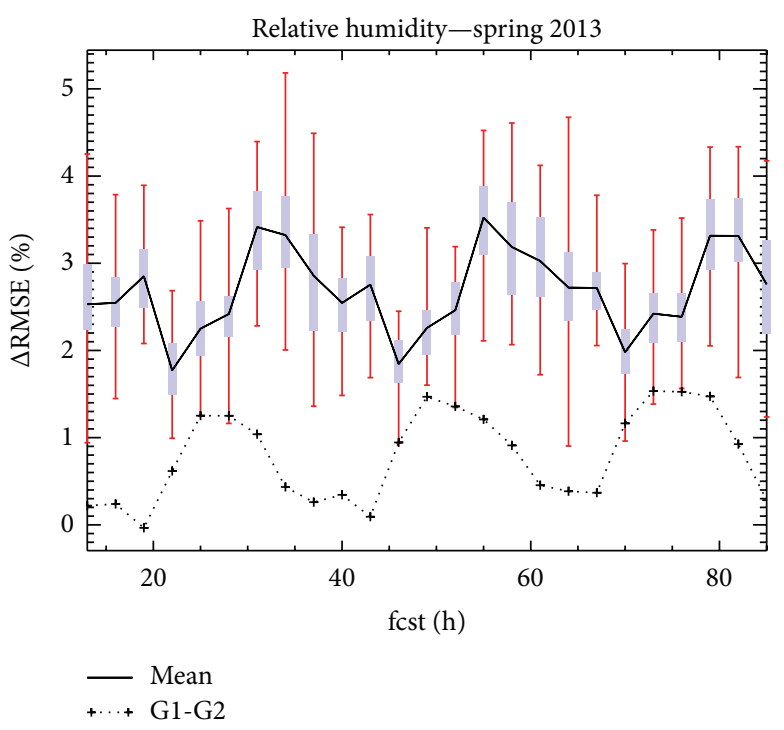

(b)

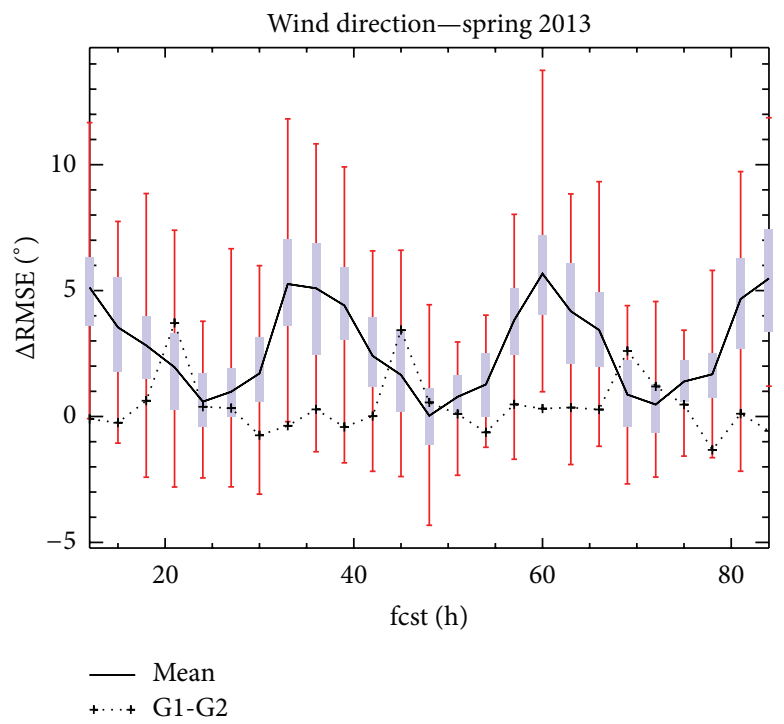

(d)

FIGURE 13: The RMSE difference ( $\triangle$ RMSE) between the forecast without and with the application of the MOS for temperature (a), relative humidity (b), wind speed (c), and wind direction (d) for different forecasting times ( $x$-axis). Positive values of $\triangle$ RMSE show an improvement of the forecast using MOS. The solid line shows the $\triangle$ RMSE averaged over the 50 applications of the MOS. The boxes delimit the 25th and 75th percentile, while the error bar spans between the maximum and minimum values of the 50 applications of the MOS. The dotted line shows the difference between the RMSEs for the model configuration with one grid ( $12 \mathrm{~km}$ horizontal resolution) and two nested grids ( $3 \mathrm{~km}$ horizontal resolution). A positive value of $\triangle$ RMSE represents a better performance for the $3 \mathrm{~km}$ horizontal resolution.

and $20 \%$ of the RMSE without MOS $(2.5 \mathrm{~m} / \mathrm{s}$, Figure $5(\mathrm{~b}))$. The result is statistically robust because all the fifty MOS applications give a forecast improvement, which is larger than $10 \%$ for most forecasting times. The improvement introduced by MOS is larger than that obtained increasing the forecast resolution from 12 to $3 \mathrm{~km}$.

Figure 13(d) shows the result of the MOS application to the forecast of the wind direction. The $\triangle \mathrm{RMSE}$ average shows positive values for all forecasting times and there is an improvement to the forecast using the MOS. However, the impact of MOS is negligible at 12 UTC and early afternoon while it increases at night, when values of $\triangle \mathrm{RMSE}$ are around $5^{\circ}$.

The results are statistically less robust for wind direction compared to other parameters because the forecast using MOS is sometimes worse than that without MOS ( $\triangle$ RMSE $<$ 0 ). Nevertheless, the 25th percentile of the $\triangle$ RMSE is positive for most of the forecasting times and especially at night, showing the usefulness of the MOS also for the forecast of the wind direction.

Finally we notice that the diurnal cycle shown by the RMSE for all parameters (Figures 3-6) mirrors in a diurnal 
cycle of $\triangle$ RMSE. For spring this occurs especially for relative humidity, wind speed and wind direction.

\section{Conclusions}

This paper shows the performance of a forecasting system, based on the RAMS model and operational at ISAC-CNR, which is focused over Southern Italy where the horizontal resolution of the model grid is $3 \mathrm{~km}$. This forecast is an upgrade of the operational setting already available in Southern Italy [24].

The forecast is performed for the following three days and the output is saved every one hour. The performance has been quantified for surface temperature, relative humidity, wind speed and wind direction, and precipitation. With the exception of precipitation, data from the GTS synoptic stations, both land (motionless) and mobile, were used for the forecast verification. This network counts 42 observing land stations over Southern Italy and a variable number of mobile reports.

A non-GTS rain gauge network, counting 135 rain gauges over Calabria, was used to verify the precipitation forecast.

The forecast performance is presented for different seasons because of the importance of the seasonal forcing on the weather and climate of Southern Italy.

Results show that RMSE is $2-3 \mathrm{~K}$ for temperature, 12$16 \%$ for relative humidity, $2.0-2.8 \mathrm{~m} / \mathrm{s}$ for wind speed and $55-75^{\circ}$ for wind direction, depending on forecasting time and season. The RMSE for different parameters shows a clear diurnal cycle, especially in summer. For example the RMSE for temperature in summer is $2 \mathrm{~K}$ during the night, while it increases up to $3.2 \mathrm{~K}$ during the day.

The increase of the RMSE with forecasting time is of the order of $10 \%$ of the initial RMSE for temperature, relative humidity, wind speed, and wind direction.

Scores for the precipitation forecast show an evident underestimation of the precipitation areas, especially for thresholds larger than $10 \mathrm{~mm} /$ day. Despite the dry behaviour of the model, the precipitation patterns are well predicted and the equitable threat score (ETS) is greater than zero for most thresholds, showing the usefulness of the forecast.

Even if it is not possible to directly compare the errors presented in this paper with those coming from others forecasting systems, because of the differences of the forecast period and of the area considered, it is interesting to discuss the results of this paper in the framework of similar works in the Mediterranean Basin.

A recent paper of Gómez et al. [37] presented the performance of a real time forecasting system based on the RAMS model with $3 \mathrm{~km}$ horizontal resolution over the Valencia region. The comparison was done against 18 surface weather stations quite uniformly distributed over the area. The analysed period is longer than that considered in this paper and covers four years (2007-2010).

Their results show a RMSE of $2-4 \mathrm{~K}$ for temperature, $15-30 \%$ for relative humidity and $2-4 \mathrm{~m} / \mathrm{s}$ for wind speed, depending on the season and forecasting time (they divided their analysis between day, i.e., 13:00 UTC, and night, i.e., 05:00 UTC). They also found a significant difference of the performance between inland and coastal stations. This difference was not discussed in our study because we did not find systematic differences between errors inland and in coastal areas. Our result, however, is, at least in part, determined by the comparatively smaller number of inland stations considered in our work.

For the precipitation forecast, the performance for POD and ETS of this paper are in line or better than those presented in [37], nevertheless the RAMS used in this paper has a much lower Bias. While part of this difference could be caused by the different areas and periods considered, the RAMS model of this paper underestimates the precipitation areas, especially for thresholds larger than $5 \mathrm{~mm} /$ day. This issue will be investigated in detail in future studies.

Another paper discussing the performance of a real time forecasting system is that of Kotroni and Lagouvardos [38]. Their work used the operational forecast issued by the MM5 [39] over the Athens area. The forecast was verified for the following two days for the year 2002 using four surface stations around and inside the urban area of Athens. Their analysis shows ABS in place of the RMSE and the results are presented for each station, while our study shows cumulative statistics over the whole of Southern Italy. In particular, the ABS for temperature is between 1.2 and $3.2 \mathrm{~K}$, ABS for wind speed is between 1.3 and $2.2 \mathrm{~m} / \mathrm{s}$ and $\mathrm{ABS}$ for wind direction is between 20 and $45^{\circ}$, depending on the season, forecasting time and station position. Our results span a larger interval of ABS performance compared to those of [38] because of the larger number of stations considered. Nevertheless, most of our ABSs are inside the values reported in [38].

The comparison above, even if qualitative, shows that the performance of the forecasting system presented in this paper is in line with others in the Mediterranean Basin and it is useful for planning future activities and developments.

An important subject investigated in this paper is the improvement of the forecast performance by statistical forecasting through MOS, with the exception of precipitation. The MOS is an effective and computational cheap way to reduce the forecast error because it compensates for model biases and for the missing of important small-scale effects that may have an important impact on the local weather.

Results show that the MOS application reduces the model error for all parameters. In particular, depending on the forecasting time, the RMSE reduction is between 20 and $30 \%$ for temperature, between 10 and $20 \%$ for relative humidity and wind speed, and between 0 and $10 \%$ for wind direction. As a consequence of the diurnal variation of the RMSE for all parameters considered, the forecast improvement by MOS shows a diurnal cycle too.

\section{Conflict of Interests}

The authors declare that there is no conflict of interests regarding the publication of this paper.

\section{Acknowledgments}

This work is partially supported by projects PON04a2 E Sinergreen-ResNovae, "Smart Energy Master for the energetic government of the territory" and PONa3_00363 "High 
Technology Infrastructure for Climate and Environment Monitoring" founded by Italian Ministry of University and Research (MIUR) PON 2007-2013. The ECMWF and CNMCA (Centro Nazionale di Meteorologia e Climatologia Aeronautica) are acknowledged for the use of the MARS (meteorological archive and retrieval system). ARPACAL is acknowledged for the rainfall data over Calabria. The authors acknowledge the anonymous reviewer for the useful and constructive comments that improved the quality of the paper.

\section{References}

[1] M. Brunetti, M. Maugeri, and T. Nanni, "Atmospheric circulation and precipitation in Italy for the last 50 years," International Journal of Climatology, vol. 22, no. 12, pp. 1455-1471, 2002.

[2] J. W. Hurrell, "Decadal trends in the North Atlantic Oscillation: regional temperatures and precipitation," Science, vol. 269, no. 5224, pp. 676-679, 1995.

[3] M. Conte, A. Giuffrida, and S. Tedesco, "The Mediterranean oscillation," in Impact on Precipitation and Hydrology in Italy Climate Water, Publications of the Academy of Finland, Helsinki, Finland, 1989.

[4] S. Federico, L. Casella, C. Bellecci, and M. Colacino, "The precipitation field over Calabria: large-scale correlations," Nuovo Cimento della Societa Italiana di Fisica C, vol. 26, no. 5, pp. 553567, 2003.

[5] G. Mastrantonio, A. P. Viola, S. Argentini et al., "Observations of sea breeze events in Rome and the surrounding area by a network of Doppler sodars," Boundary-Layer Meteorology, vol. 71, no. 1-2, pp. 67-80, 1994.

[6] R. Ferretti, G. Mastrantonio, S. Argentini, R. Santoleri, and A. Viola, "A model-aided investigation of winter thermally driven circulation on the Italian Tyrrhenian coast: a case study," Journal of Geophysical Research, vol. 108, no. D24, 2003.

[7] S. Federico, L. Pasqualoni, L. de Leo, and C. Bellecci, "A study of the breeze circulation during summer and fall 2008 in Calabria, Italy," Atmospheric Research, vol. 97, no. 1-2, pp. 1-13, 2010.

[8] A. Buzzi, M. D’Isidoro, and S. Davolio, "A case-study of an orographic cyclone South of the Alps during the MAP SOP," Quarterly Journal of the Royal Meteorological Society, vol. 129, no. 591, pp. 1795-1818, 2003.

[9] N. G. Prezerakos, "Synoptic flow patterns leading to the generation of north-west African depressions," International Journal of Climatology, vol. 10, no. 1, pp. 33-48, 1990.

[10] A. Speranza, "The physical mechanisms of secondary cyclogenesis," in Recent Research Developments in Atmospheric Science, vol. 1, Research Signpost, Kerala, India, 2001.

[11] J. Campins, A. Jansà, and A. Genovés, "Three-dimensional structure of western Mediterranean cyclones," International Journal of Climatology, vol. 26, no. 3, pp. 323-343, 2006.

[12] A. Moscatello, M. M. Miglietta, and R. Rotunno, "Numerical analysis of a mediterranean "Hurricane" over Southeastern Italy, Monthly Weather Review, vol. 136, no. 11, pp. 4373-4397, 2008.

[13] S. Federico, C. Bellecci, and M. Colacino, "Quantitative precipitation forecast of the Soverato flood: the role of orography and surface fluxes," Nuovo Cimento della Societa Italiana di Fisica C, vol. 26, no. 1, pp. 7-22, 2003.

[14] V. Kotroni, K. Lagouvardos, G. Kallos, and D. Ziakopoulos, "Severe flooding over central and southern Greece associated with pre-cold frontal orographic lifting," Quarterly Journal of the Royal Meteorological Society, vol. 125, no. 555, pp. 967-991, 1999.

[15] M. M. Miglietta and R. Rotunno, "Numerical simulations of conditionally unstable flows over a mountain ridge," Journal of the Atmospheric Sciences, vol. 66, no. 7, pp. 1865-1885, 2009.

[16] R. Rotunno and R. Ferretti, "Mechanisms of intense alpine rainfall," Journal of the Atmospheric Sciences, vol. 58, no. 13, pp. 1732-1749, 2001.

[17] S. Federico, E. Avolio, C. Bellecci, A. Lavagnini, M. Colacino, and R. L. Walko, "Numerical analysis of an intense rainstorm occurred in southern Italy," Natural Hazards and Earth System Science, vol. 8, no. 1, pp. 19-35, 2008.

[18] A. Jansa, P. Alpert, P. Arbogast et al., "MEDEX: a general overview," Natural Hazards and Earth System Science, vol. 14, no. 8, pp. 1965-1984, 2014.

[19] H. R. Glahn and D. A. Lowry, "The use of Model Output Statistics (MOS) in objective weather forecasting," Journal of Applied Meteorology, vol. 11, no. 8, pp. 1203-1211, 1972.

[20] G. M. Carter, J. P. Dallavalle, and H. R. Glahn, "Statistical forecasts based on the National Meteorological Center's numerical weather prediction system," Weather and Forecasting, vol. 4, no. 3, pp. 401-412, 1989.

[21] E. Kalnay, Atmospheric Modeling, Data Assimilation and Predictability, Cambridge University Press, Cambridge, UK, 2002.

[22] D. S. Wilks, Statistical Methods in the Atmospheric Sciences, Academic Press, New York, NY, USA, 2006.

[23] W. R. Cotton, R. A. Pielke Sr., R. L. Walko et al., "RAMS 2001: current status and future directions," Meteorology and Atmospheric Physics, vol. 82, no. 1-4, pp. 5-29, 2003.

[24] S. Federico, "Verification of surface minimum, mean, and maximum temperature forecasts in Calabria for summer 2008," Natural Hazards and Earth System Science, vol. 11, no. 2, pp. 487500, 2011.

[25] R. L. Walko, L. E. Band, J. Baron et al., "Coupled atmospherebiophysics-hydrology models for environmental modeling," Journal of Applied Meteorology, vol. 39, no. 6, pp. 931-944, 2000.

[26] R. L. Walko, W. R. Cotton, M. P. Meyers, and J. Y. Harrington, "New RAMS cloud microphysics parameterization part I: the single-moment scheme," Atmospheric Research, vol. 38, no. 1-4, pp. 29-62, 1995.

[27] J. Molinari and T. Corsetti, "Incorporation of cloud-scale and mesoscale downdrafts into a cumulus parameterization: results of one and three-dimensional integrations.," Monthly Weather Review, vol. 113, no. 4, pp. 485-501, 1985.

[28] H. L. Kuo, "Further studies of the parameterization of the influence of cumulus convection on large-scale flow," Journal of the Atmospheric Sciences, vol. 31, no. 5, pp. 1232-1240, 1974.

[29] J. Smagorinsky, "General circulation experiments with the primitive equations. Part I, the basic experiment," Monthly Weather Review, vol. 91, no. 3, pp. 99-164, 1963.

[30] R. A. Pielke, Mesoscale Meteorological Modeling, Academic Press, San Diego, Calif, USA, 2002.

[31] C. Chen and W. R. Cotton, "A one-dimensional simulation of the stratocumulus-capped mixed layer," The Boundary-Layer Meteorology, vol. 25, no. 3, pp. 289-321, 1983.

[32] S. Federico, E. Avolio, C. Bellecci, and M. Colacino, "On the performance of a limited area model for quantitative precipitation forecast over Calabria," Il Nuovo Cimento C, vol. 26, no. 6, pp. 663-676, 2003. 
[33] S. Federico, L. Pasqualoni, A. M. Sempreviva et al., "The seasonal characteristics of the breeze circulation at a coastal Mediterranean site in South Italy," Advances in Science and Research, vol. 4, pp. 47-56, 2010.

[34] J. E. Simpson, Sea Breeze and Local Winds, Cambridge University Press, New York, NY, USA, 1994.

[35] S. Federico, E. Avolio, L. Pasqualoni, L. De Leo, A. M. Sempreviva, and C. Bellecci, "Preliminary results of a 30-year daily rainfall data base in southern Italy," Atmospheric Research, vol. 94, no. 4, pp. 641-651, 2009.

[36] O. A. Sindosi, A. Bartzokas, V. Kotroni, and K. Lagouvardos, "Verification of precipitation forecasts of MM5 model over Epirus, NW Greece, for various convective parameterization schemes," Natural Hazards and Earth System Science, vol. 12, no. 5, pp. 1393-1405, 2012.

[37] I. Gómez, V. Caselles, and M. J. Estrela, "Real-time weather forecasting in the Western Mediterranean Basin: an application of the RAMS model," Atmospheric Research, vol. 139, pp. 71-84, 2014.

[38] V. Kotroni and K. Lagouvardos, "Evaluation of MM5 highresolution real-time forecasts over the urban area of Athens, Greece," Journal of Applied Meteorology, vol. 43, no. 11, pp. 16661678, 2004.

[39] J. Dudhia, "A nonhydrostatic version of the Penn State-NCAR mesoscale model: validation tests and simulation of an Atlantic cyclone and cold front," Monthly Weather Review, vol. 121, no. 5, pp. 1493-1513, 1993. 

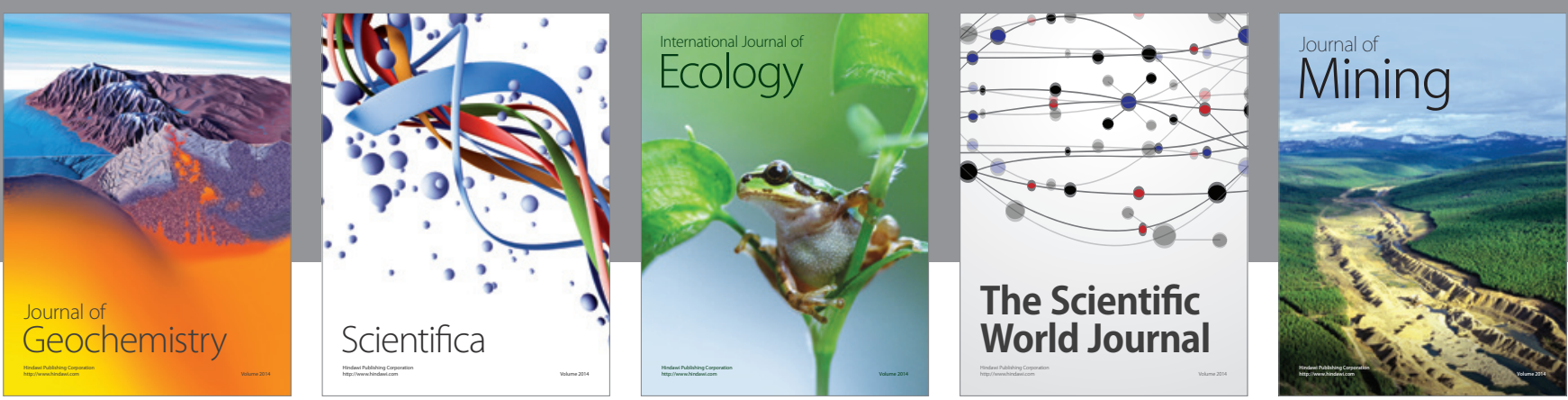

The Scientific World Journal
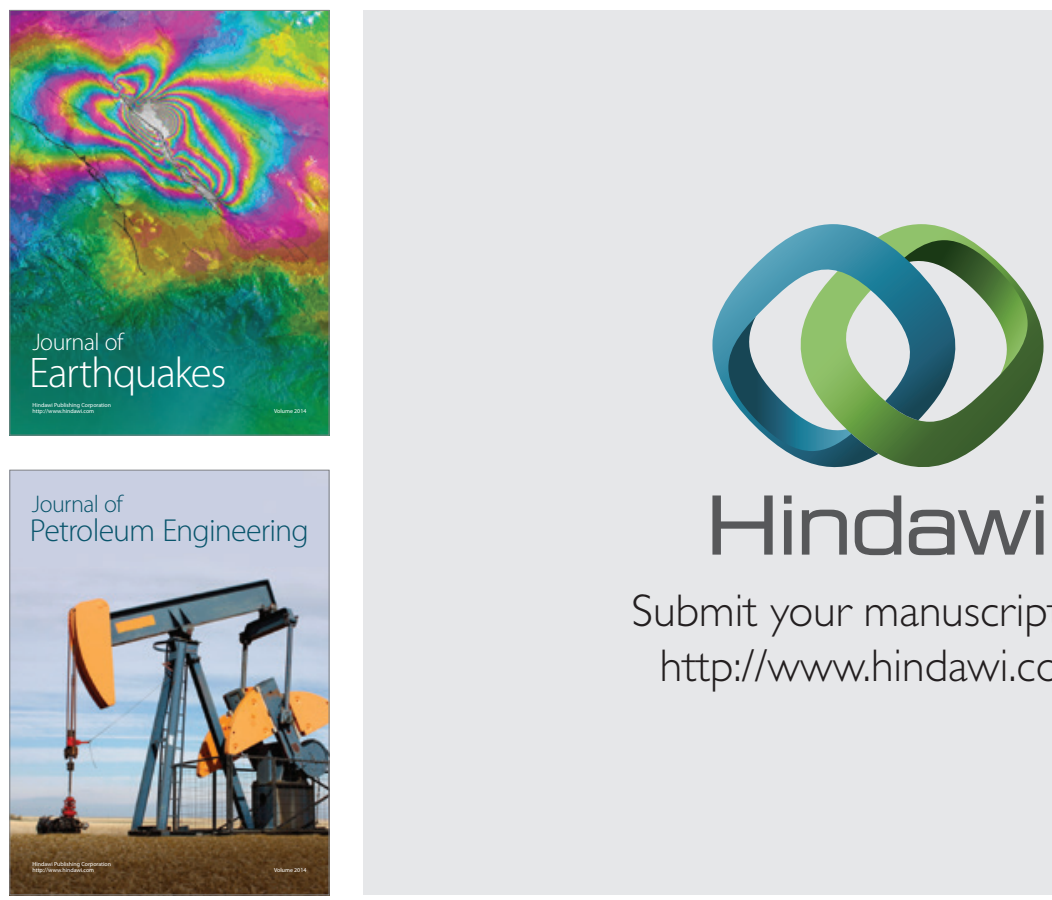

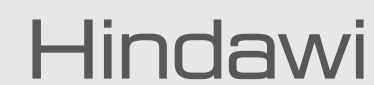

Submit your manuscripts at

http://www.hindawi.com
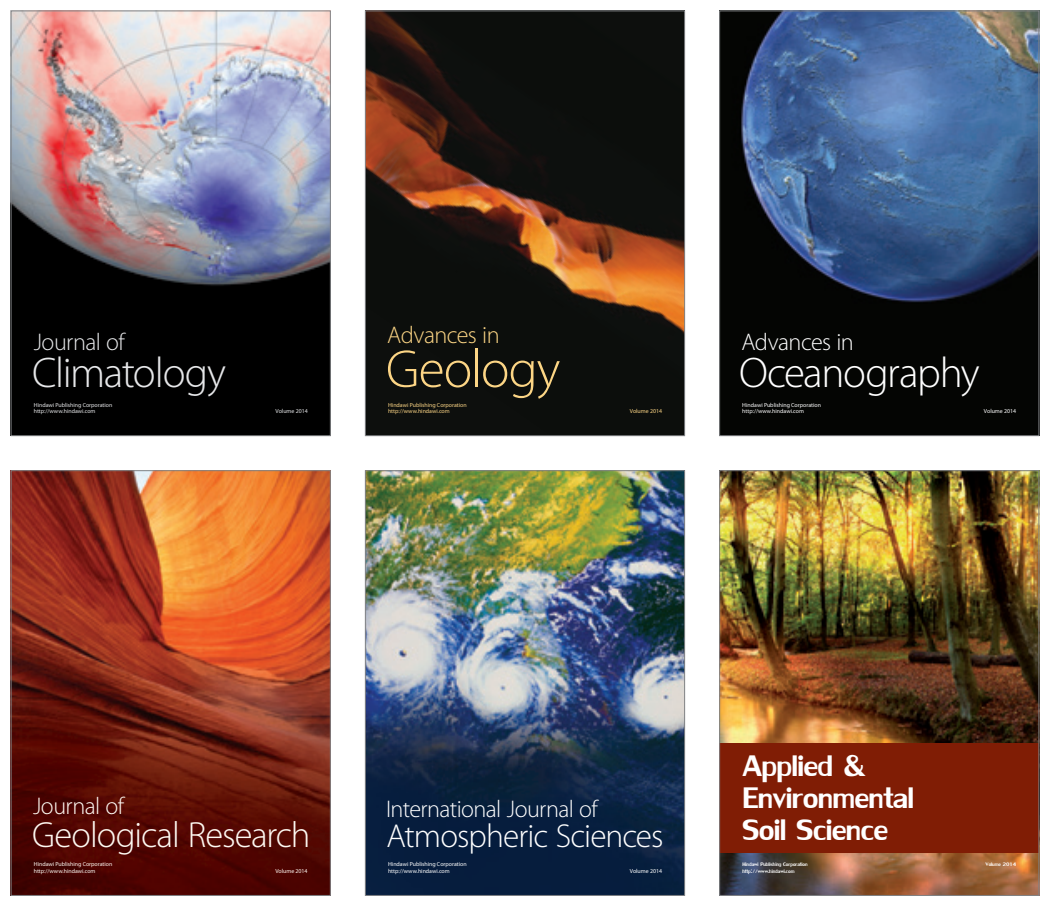
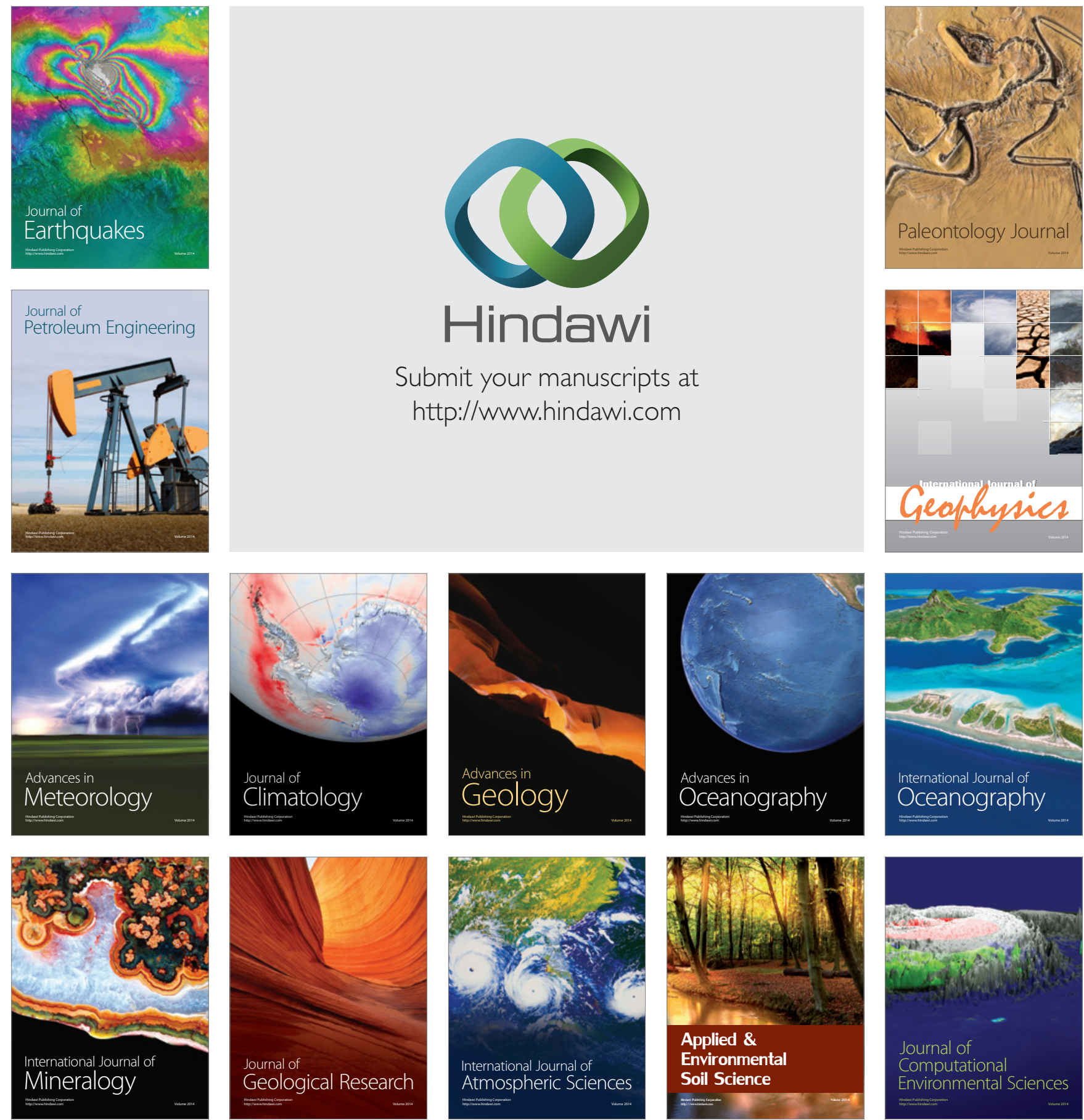